\title{
PENDIDIKAN KRISTEN \\ DALAM PELAYANAN PENGEMBALAAN
}

\author{
Simon Runtung
}

Intisari

Tugas dan panggilan Gereja tentang pendidikan Kristen sering mendapat pemahaman yang keliru bahwa pendidikan Kristen itu hanya merupakan salah satu mata pelajaran yang diajarkan disekolah-sekolah dan tidak terlalu penting dalam pelayanan pengembalaan. Sesungguhnya pendidikian Kristen adalah tugas yang sentral dari Gereja Yesus Kristus

\section{Pendahuluan}

Pendidikan Kristen merupan suatu wadah yang sangat penting untuk pengembangan jemaat, namun sering dilalaikan dalam jemaat. Pada dasarnya Tuhan menghendaki agar jemaat-Nya bertumbuh dengan menggunakan hamba-hambanya sebagai metode. Tanpa adanya kesadaran dan tanggung jawab akan beban ini, maka pertumbuhan yang dikehendaki Allah bagi jemaat-Nya akan tetap menjadi impian belaka. Lebih dari itu kelalaian melakukan tugas ini berarti ketidaktaatan kepada kehendak Allah.

Untuk menanamkan kesadaran dan mewujudkan beban tersebut, perlu adanya pengertian serta pendalaman tentang suatu wadah yang ampuh yang telah diprogramkan Allah untuk pembangunan jemaat-Nya. Wadah itu adalah pendidikan Kristen. ${ }^{1}$

Tugas dan panggilan gereja tentang pendidikan Kristen sering mendapat pemahaman yang keliru bahwa pendidikan Kristen itu hanya merupakan salah satu mata pelajaran yang diajarkan di sekolahsekolah dan tidak terlalu penting dalam pelayanan penggembalaan. Sesengguhnya Pendidikan Kristen adalah tugas yang sentral dari gereja Yesus Kristus. Jackie L. Smallbones seorang ahli Pendidikan Kristen berkata, "Jika gereja Yesus Kristus memiliki misi yang benar dalam dunia ini maka seharusnya memberi perhatian khusus kepada pengajar dan pendidikan seseorang. Yesus memanggil murudmurid-Nya untuk pergi kepada setiap bangsa untuk memberitakan Injil dan mendidik (Mat. 28:19-20). Pedidikan Kristen seharusnya menjadi fokus yang sentral dari gereja Yesus Kristus." 2

Kenyataan yang terjadi di manamana ialah petobat-petobat yang dihasilkan oleh pelayanan penginjilan pada harihari ini sangat sedikit sekali yang tetap tinggal dan bertumbuh dan berbuah di dalam gereja lokal. Banyak di antara mereka kembali lagi ke dalam hidup yang lama. Cruch Grout Magazine melaporkan dari jumlah mengambil keputusan yan $q$ maju ke depan dalam pelayanan penginjilan hanya $6 \%$ yang tinggal setia di gereja lokal, sedangkan $94 \%$ terhilang. Menurut Bill Gothard dalam bukunya The Sevev Fold Power of Frist Century Church and Houses, bahwa menurut sebuah lembaga yang khusus melakukan pelayanan tindak lanjut bagi pengambil keputusan, keberhasilanya sangatlah sedikit. Lembaga yang tak disebut namanya tersebut melaporkan bahwa apabila dilakukan usaha yang paling maksimal pun palingpaling hanya $10 \%$ yang dapat dijangkau dan setia di gereja. Umumnya hanya $3 \mathrm{~s} / \mathrm{d}$ 5 persen. Bahkan menurut beberapa misiolog, hasil pelayanan penginjilan yang tidak ditindaklanjuti hanya akan menghasilkan $3 \mathrm{~s} / \mathrm{d} 4$ persen setia, bertum- 
buh dan berbuah daiam jemaat. Padahal dalam gereja mula-mula boleh dikatakan hampir $100 \%$ dari ketiga ribu mengambil keputusan tersebut setia, bertekun, dalam pengajaran, memecah-mecahkan roti, persekutuan dan doa di dalam gereja (Kis. 2:41-42). Hal ini bisa terjadi karena pasti ada konsep yang keliru tentang Pendidikan Kristen. ${ }^{3}$

Pada umumnya gereja belum memahami tentang pentingnya pendidikan Kristen, sehingga tidak memperoleh porsi yang benar dalam program-program gereja. Itulah sebabnya seorang teolog sekaligus ahli pendidikan Kristen Robert R. Boehle berkata, "Pendidikan Kristen adalah suatu gagasan yang penting dari gereja untuk seluruh anggota gereja." ${ }^{4}$ Dalam sejarah gereja umum kisah mulia pendidikan Kristen jarang mendapat perhatian yang bermakna. Pada umumnya pelayanan itu hanya disebutkan sepintas lalu dalam rangka memaparkan pergumulan gereja dan pertentangan teologis dan persoalan gerejawi. Rupanya pertentangan teologis lebih menarik ketimbang pikiran teolog dan awam tentang pendidikan Kristen dan pembinaan di kalangan jemaat.

Masalah pendidikan Kristen juga dikemukakan oleh Kenneth O. Gangel yakni kurangnya pengetahuan tentang Alkitab yang murni di kalangan orang dewasa. Berbagai alasan dapat dikemukakan untuk menjelaskan kekurangan ini tetapi yang pasti alasan utamanya adalah tidak memadainya program pendidikan Kristen dan kurangnya kepemimpinan di gereja lokal ${ }^{5}$ Pendidikan Kristen ini dalam pengembangan jemaat perlu mendapat pemahaman yang mendalam dari jemaat Tuhan secara umum dan gembala pada khususnya.

Berdasarkan latar belakang tersebut di atas maka masalah pokok yang akan dikedepankan dalam penulisan ini ialah Apakah makna Pendidikan Kristen dan Mengapa Pendidikan Kristen itu penting dalam pelayanan pengembalaan?

\section{Makna Pendidikan Kristen}

Pendidikan Kristen adalah upaya mengajar, mendidik dan membentuk anggota jemaat Yesus Kristus supaya mereka belajar untuk hidup bersama-sama dengan Allah di bawah pimpinan Roh kudus, dan di dalam persekutuan dengan Yesus Kristus Anak-Nya. Dengan jalan demikian mereka menjadi anggota gereja Tuhan yang dipersiapkan dan diperlengkapi untuk tugas kesaksian dan pelayanan mereka di dunia. ${ }^{6}$

Pendidikan Kristen adalah upaya untuk menolong seseorang untuk datang dan mengenal kristus serta tinggal di dalam Dia atau hidup di dalam Dia dan menolong mereka mengerti apa arti kekristenan dalam dunia ini. ${ }^{7}$

Pendidikan Kristen adalah upaya untuk membawa para murid ke dalam pengenalan yang benar tentang Tuhan, yang melibatkan relasi yang intim dengan Tuhan. Relasi ini tidak dapat terealisasi hanya dengan mengetahui fakta-fakta pengetahuan tentang Tuhan. Penekanan pengetahuan tentang fakta-fakta mengenai Tuhan inilah yang menjadi pangkal kejenuhan yang membawa ketidaktertarikan jemaat pada pengajar gereja. Gereja perlu kembali pada pengertian tentang mengenal Allah untuk menumbuhkan kembali gairah dalam pengajaran gereja. Pengenalan akan Allah yang dimengerti sebagai terjadinya hubungan yang intim dengan Allah merupakan adanya suatu indikasi adanya suatu dinamika hidup dalam pengajaran gereja. ${ }^{8}$

Pendidikan Kristen dapat saja diartikan sebagai pendidikan yang Kristen. Artinya pendidikan yang bercorak, berdasar, dan berorientasi Kristiani. Pendidikan Kristen juga merupakan upaya sadar dan bersahaja serta sadar tujuan. Selain itu berlangsung dalam konteks tertentu dengan pendekatan atau strategi tertentu serta memberi perhatian terhadap isi tertentu pula. ${ }^{9}$ 
Pendidikan Kristen merupakan usaha bersahaja dan sistematis, ditopang oleh upaya rohani dan manusiawi untuk menstransmisikan pengetahuan, nilai-nilai, sikap-sikap, keterampilan-keterampilan dan tingkah laku yang bersesuaian atau konsisten dengan iman Kristen; mengupayakan perubahan, pembaruan dan reformasi pribadi-pribadi, kolompok bahkan struktur oleh kuasa Roh Kudus, serta peserta didik hidup sesuai dengan kehendak Allah sebagaimana yang diajarkan oleh Alkitab terutama dalam Yesus Kristus. ${ }^{10}$

Pendidikan Kristen adalah tugas gereja untuk mengkomunikasikan dan membagi-bagikan warisan kebenarankebenaran Kristen kepada umat-Nya dan kepada dunia. Pengajaran ini diberikan dalam bentuk ajaran gerejawi. ${ }^{11}$

Pendidikan Kristen ialah kesadaran akan hadirnya Roh kudus dalam kehidupan umat manusia, kesadaran akan Kristus, dan menghargai Pribadi Kristus serta ajaran-Nya, mengembangkan watak Kristus, berpartisipasi dalam pembangunan masyarakat, berpartisipasi dalam pembangunan gereja dan menganut falsafah hidup Kristus. ${ }^{12}$

Pendidikan Kristen adalah tugas pemuridan yang diamanatkan oleh Kristus kepada jemaat-Nya. Pendidikan Kristen berarti pelayanan pemuridan dalam jemaat Tuhan. Pelayanan itu diamanatkan oleh Tuhan Yesus sendiri. Menurut Amanat Agung, pemuridan melalui pengajaran bukan suatu pilihan melainkan suatu amanat yang harus ditaati, bukan pekerjaan sampingan, melainkan salah satu pelayan pokok, bukan ditujukan secara khusus kepada kaum wanita, melainkan untuk setiap anak Tuhan. Pendidikan Kristen memegang peranan penting dalam keseluruhan program jemaat.

Pendidikan Kristen adalah Proses pendewasaan. Artinya pendidikan yang merupakan suatu proses yang berpusat pada Kristus, didasarkan pada Alkitab, membimbing orang melalui firman Tuhan dan pekerjaan Kristus, menghasilkan pertumbuhan rohani dan bertujuan mendewasakan seseorang dalam Kristus. Proses tersebut dijelaskan dalam II Timotius 3:15-17, proses pendidikan Kristen dimulai pada saat membawa seseorang kepada pengenalan akan Tuhan Yesus Kristus. Ia diajar untuk mengenal kitab suci yang dapat memberi hikmat dan menuntun kepada keselamatan oleh iman kepada Yesus Kristus. Setelah seseorang diselamatkan selanjutnya ia betumbuh melalui pengajaran firman Tuhan. Setiap orang yang telah diselamatkan menerima pengajaran dari firman Tuhan dan diperlengkapi untuk setiap perbuatan baik sebagai buah imannya kepada Kristus.

Pendidikan Kristen adalah program pengkaderan. Pendidikan dalam jemaat adalah pekerjaan Tuhan melalui orangorang yang telah dipercayakan-Nya untuk mengajar dan mempersiapkan orang lain bagi pekerjaan itu juga (II Tim. 2:2). Sebagai pendidik jemaat, Paulus mengajar Timotius untuk meneruskan tugas pendidikan itu kepada orang lain dalam Jemaat. Inilah yang disebut siklus pemuridan, di mana para pendidik melipatgandakan dalam pelayanan dan kehidupan murid-murid yang menerima ajaran mereka.

Pendidikan Kristen adalah sarana untuk memperlengkapi seluruh anggota jemaat bagi pekerjaan pelayanan. Rencana Allah bagi jemaat-Nya ialah pertumbuhan menuju kedewasaan. Namun pertumbuhan itu hanya dapat berlangsung bila setiap orang percaya ikut serta dalam pelayanan. Pendidikan Kristen adalah wadah dan sarana untuk mendidik, mempersiapkan dan memperlengkapi seluruh anggota jemaat sehingga memiliki pegetahuan dan keterampilan untuk dapat melibatkan diri dalam pekerjaan pelayanan kepada Tuhan. Pendidikan Kristen dalam jemaat berfungsi membangun tubuh Kristus melalui pembinaan dan partisipasi anggota, sehingga jemaat memenuhi maksud Allah bagi-Nya. 
Pendidikan Kristen adalah tanggung jawab pemimpin jemaat. Pemimpin jemaat merupakan karunia Allah bagi Jemaat (Ef. 4:11-16). Dalam ayat ini terdapat beberapa ungkapan yang mengandung unsur pendidikan, dan sekaligus menjadi pedoman bagi para pemimpin dalam jemaat Tuhan. Tugas pendidikan tersebut adalah: memperlengkapi orangorang kudus bagi pekerjaan pelayanan, membangun tubuh Kristus, mencapai kesatuan iman dan pengetahuan yang benar tentang Anak Allah, mencapai kedewasaan penuh dalam segala hal ke arah Kristus, menerima pertumbuhan dan membangun dirinya dalam kasih. ${ }^{13}$.

Pendidikan Kristen adalah pelayanan kegerejaan yang membimbing orang tua untuk memenuhi panggilannya sebagai orang tua Kristen dan sekaligus pula memperlengkapi warga jemaat untuk hidup sebagai anggota persekutuan yang beribadah, bersaksi, mengajar, belajar dan melayani atas nama Yesus Kristus. ${ }^{14}$

\section{Pentingnya Pendidikan Kristen}

Seorang guru perlu memiliki pondasi yang kuat mengapa pendidikan Kristen itu penting khususnya ditinjau dari perspektif iman Kristen. Paling tidak jika gembala memahami perlunya tugas mengajar maka ia akan memiliki daya dorong di dalam rangka meningkatkan kualitas pelayanannya demi peningkatan mutu hidup peserta didiknya. Bagi para pendidik Kristen (guru, pendeta, bahkan majelis jemaat) pemahaman yang benar dari segi landasan tugas mengajar ini dapat menjadi modal dasar yang amat berharga untuk menghadapi berbagai kendala pelayanan secara kreatif, konstruktif dan realistis.

\section{Mendidik adalah Program Allah sendiri}

Seluruh Alkitab memperlihatkan Allah sebagai pendidik. Melalui proses pendidikan, Allah menyatakan wahyu-Nya secara bertahap dan membina manusia untuk mengenal Dia dan kehendak-Nya bagi mereka. "Aku handak mengajar dan menunjukkan kepadamu jalan yang harus kau tempuh, Aku hendak memberi nasehat, mata-Ku tertuju kepadamu" (Maz. 32:8).

Alkitab sebagai sumber dasar iman Kristiani menjelaskan bahwa dalam hal membimbing manusia untuk lebih mengenal Dia, Allah berperan sebagai pengajar. Sebagai pengajar la aktif memberitahukan kebenaran. Kebenaran itu sendiri adalah pribadi-Nya, firman-Nya, dan perbuatanNya.

Ia sudah, sedang bahkan terusmenerus berkomunikasi dengan manusia dalam berbagai cara (Ibr. 1:1-2). Allah adalah pengajar yang tiada taranya (Ayb. 36:22) dan tak ada yang dapat mengajari Allah (Ayb. 21:22, Yes. 40:14). Allah mengajari manusia supaya memiliki pengetahuan (Maz. 94:10).

\section{Hal Mendidik Itu Diperintahkan Allah ${ }^{15}$}

Sejak semula Allah menyatakan bahwa umat-Nya harus diajar dan dibina dalam segi kehidupannya sehari-hari: hidup beribadah, hidup berumah tangga, pekerjaan, hidup bermasyarakat, hubungan antarpribadi, nilai-nilai, norma-norma, dan sebagainya. Hukum Taurat diberikan sebagai ajaran dasar yang diperlakukan oleh umat-Nya itu. Allah memerintahkan Musa untuk mengajarkan hukumhukumnya itu kepada bangsa Israel agar mereka melakukannya dan diberkati serta menjadi berkat.

"Inilah perintah yakni ketetapan dan peraturan, yang aku ajarkan kepadamu atas perintah TUHAN, Allahmu, untuk dilakukan di negeri, ke mana kamu pergi untuk mendudukinya, supaya seumur hidupmu engkau dan anak cucumu takut akan TUHAN, Allah dan berpegang kepada segala ketetapan dan perintah yang kusampaikan kepadamu dan supaya lanjut umurmu. ...lakukanlah itu dengan setia, supaya baik keadaanmu..." (Ul. 6:1-3a). 
Allah tidak mempunyai tangan kecuali tangan kita, untuk melaksanakan pekerjaan-Nya saat ini, Ia tidak mempunyai kaki kecuali kaki kita untuk menuntun manusia ke jalan-Nya, Ia tidak mempunyai mulut kecuali mulut kita untuk memberitakan kepada manusia tentang apa yang diinginkan-Nya. ${ }^{16}$

\section{Hal Mendidik Itu Diberkati Allah}

Sejarah Perjanjian Lama membuktikan bahwa keberhasilan dan kemajuan umat Allah adalah hubungannya dengan pendidikan yang diterima mereka. Di padang gurun dan di Kanaan, Allah membina umatNya yang pernah menjadi budak di Mesir itu menjadi bangsa yang disegani bangsa-bangsa lain.

Sayangnya kemudian umat Tuhan itu melalaikan ajaran Tuhan sehingga mengalami kemunduran dan kekalahan pada zaman hakim-hakim. Namun mereka kembali menikmati kemajuan pada zaman Samuel karena hasil program pendidikan yang dikembangkan oleh nabi yang terkenal itu. Kebangunan rohani yang terjadi setelah zaman pembuangan, ketika Ezra mengajarkan firman Allah kepada umat Israel sehingga mereka mengerti dan menaatinya (Neh. 8). Umat bersukacita dan hidup sejahtera. Allah menetapkan bahwa pengajaran firman-Nya akan diberkati dan membawa berkat.

\section{Yesus Sendiri Mengutamakan Hal Mendidik}

Pelayanan Yesus menunjukkan pentingnya pengajaran. Ia menaati rencana Allah untuk mengajar (Yoh. 8:26). Yesus terkenal sebagai Guru atau "Rabi". Selama tiga tahun Ia mengutamakan hal mengajar. Pada waktu itu seluruh penduduk Palestina telah mendengar ajaran-Nya, tetapi yang lebih penting bagi-Nya adalah pelayananNya kepada murid-murid-Nya. Tuhan Yesus mengkhususkan banyak waktu untuk mendidik kelompok inti itu. Melalui pengajaran-Nya dalam konteks hidup dan pelayanan bersama sehari-hari, Yesus mengubah sekelompok orang yang sederhana dan penuh kekurangan menjadi sebarisan orang yang meneruskan pekerjaan-Nya dan mengubah sejarah dunia.

Yesus adalah teladan orang percaya. Kalau hal mengajar itu penting bagi Yesus, itu juga penting bagi jemaat-Nya sampai hari ini.

\section{Yesus Memberikan Perintah Untuk Mendidik}

Bukan saja teladan Yesus Kristus tetapi juga amanat-Nya menyatakan bahwa pendidkan Kristen adalah tugas penting yang tidak boleh ditawar-tawar.

Perintah utama amanat Agung Tuhan Yesus dalam Matius 28:19-20 adalah: "JADIKANLAN SEMUA BANGSA MURIDKU," yaitu menjadikan semua orang murid-Nya yang percaya dan taat kepada-Nya. Ada dua unsur mutlak dalam proses pemuridan ini. Unsur Penginjilan: "Pergilah...babtislah..." dan unsur pendidikan ialah: "ajarlah". Orang percaya ditugaskan untuk menginjili orang supaya percaya dan mendidik mereka secara terusmenerus supaya semakin sempurna dan semakin dewasa dalam Kristus. Melalaikan unsur pendidikan atau pembinaan ini berarti tidak memenuhi tuntutan amanat Agung. Ini juga berarti melemahkan gereja Kristus, sekalipun penginjilan sudah berhasil dilakukan.

\section{Gereja Mula-Mula Menjalankan Pendidikan Kristen dan Berkembang}

Murid-murid Kristus pada abad pertama menaati perintah Yesus. Mereka meneruskan pelayanan menginjli dan mengajar. Ke mana-mana mereka memberitakan Injil, walaupun mereka mengalami perlawanan sengit. Di tempat-tempat baru, kuasa Injil itu memunculkan suatu dinamika baru yaitu umat Allah yang tergabung dalam suatu persekutuan rohani yang nyata sebagai jemaat setempat.

Orang-orang percaya yang mulamula itu segera menyadari dwitugas 
mereka yaitu ke luar kepada dunia dan ke dalam kepada anggota jemaat sendiri. Kedua tugas ini saling menunjang dan berjalan seiring. Jemaat Kristus pada abad pertama itu berkembang pesat dan berpengaruh di seluruh dunia karena adanya kesempatan yang diberikan untuk mengadakan pembinaan atau pelayanan ke dalam. Para petobat baru segera diajar, dididik agar bertumbuh menjadi dewasa dalam iman dan dilibatkan dalam pelayanan jemaat. Kitab Kisah Para Rasul mengatakan, "Dan setiap hari mereka melanjutkan pengajaran mereka di Bait Allah dan di rumah-rumah orang dan memberitakan Injil tentang Yesus yang adalah Mesias" (Kis. 5:42).

\section{Rasul Paulus Mementingkan Hal Mendidik}

Paulus, yang merintis banyak jemaat, menjelaskan betapa pentingnya pelayanan pendidikan Kristen itu, "Tiaptiap orang kami ajari dalam segala hikmat, untuk memimpin tiap-tiap orang kepada kesempurnaan di dalam Kristus" (Kol. 1:28).

Rasul Paulus juga memberikan instruksi kepada Timotius untuk menjalankan program pendidikan yang berkesinambungan, "Apa yang telah engkau dengar dari padaku di depan banyak saksi, percayakanlah itu kepada orang-orang yang dapat dipercayai, yang juga cakap mengajar orang lain" (II Tim. 2:2).

Di setiap jemaat, Paulus mempunyai pelayanan mengajar. Ia bersama Barnabas tinggal di Anthiokia dan mengajar di jemaat yang baru berdiri itu (Kis. 11:26). Kemudian jemaat meneruskan pelayanan mengajar tersebut. Semakin banyak orang yang percaya, semakin banyak pula orang yang dilibatkan dalam program pendidikan Kristen di Jemaat itu (Kis. 13:1; 15:35).

Di Korintus Paulus tinggal satu setengah tahun, sambil mengajarkan firman Allah kepada orang banyak (Kis.
18:11). Di Efesus juga hampir selama tiga tahun ia mengajar anggota jemaat, baik di muka umum maupun dalam perkumpulan-perkumpulan di rumah (Kis. 20:20b).

Meskipun Paulus harus meninggalkan suatu jemaat, ia tetap terbeban untuk mendidik jemaat itu. Semua surat kirimannya bersifat mengajar. Bahkan sungguh menarik bahwa surat-surat yang dikirimkannya jarang memberikan petunjukpetunjuk bagi penginjilan langsung. Yang ditekankan dalam surat-surat itu ialah asas kepercayaan yang benar dan cara hidup yang sesuai dengan pengakuan iman itu.

Mengapa Paulus mengutamakan ajaran tentang cara hidup dan mutu persekutuan yang benar-benar pada anakanak Tuhan? Alasannya ialah karena kuasa Injil menjadi nyata melalui kehidupan umat Allah sehari-hari. Bahkan kesempatan menginjili semakin terbuka secara wajar melalui kehidupan orangorang percaya yang menyatakan kasih dan kemurnian hidup Allah. Pengaruh gereja yang mula-mula besar sekali terutama karena perubahan hidup orang percaya dan kualitas hidup bersama yang ditunjukkan mereka. Perwujudan kuasa Injil ini yang dinyatakan dalam hidup sehari-hari dapat dihasilkan oleh firman Allah dan oleh Roh Allah.

\section{Hal Mendidik Dibutuhkan dan Bermanfaat}

Pelayanan pengajaran dibutuhkan dan bermanfaat, menghasilkan jemaat yang bertumbuh dan kuat. Itulah sebabnya Allah memberikan kepada jemaat-Nya orang-orang yang berkarunia mengajar. "Dan Ialah yang memberikan, baik rasulrasul maupun nabi-nabi, baik pemberitapemberita Injil maupun gembala-gembala dan pengajar-pengajar, untuk memperlengkapi orang-orang kudus bagi pekerjaan pelayanan, bagi pembangunan tubuh Kristus" (Ef. 4:11-12).

Melalui pembinaan jemaat, warga jemaat mengerti dasar imannya dan 
menyatakan imannya itu dalam segala situasi dan kondisi hidup sambil menyatakan jawaban firman Allah atas segala persoalan hidup. Melalui pengajaran firman Allah, warga jemaat menjadi garam dan terang di tempat di mana mereka berada. Inilah peranan pendidikan Kristen dan peranan ini sangat penting bagi pertumbuhan gereja dan perluasan kerajaan Allah.

Dalam Perjanjian Lama (PL) dan Perjanjian Baru (PB) terdapat beberapa istilah yang berkaitan dengan pendidikan yang sangat bermanfaat:

\section{Perjanjian Lama}

Pertama, Lamath (Ul. 4:5,10; Yer. 31:34). Artinya memukul dengan tongkat dan memberikan dorongan bagi perbuatan. Jadi fokus utama pendidikan ialah mendisiplin, mendorong, membimbing dan melatih orang untuk takut kepada Tuhan.

Kedua, Be-en (Maz. 119:34). Artinya menanggapi, memahami, mengerti, dan mampu memisahkan. Mendidik berarti memampukan orang untuk mengerti dalam arti mampu membedakan mana yang baik dan mana yang buruk.

Ketiga, Alaph (Ams. 22:25). Mendidik berarti memampukan seseorang untuk mengenal secara dekat dan semakin jelas.

Keempat, Yada (Kej. 18:19). Mendidik berarti mengusahakan agar seseorang dapat menegetahui apa yang diajarkan.

Kelima, Yara (Kel. 14:12,15). Artinya menampakkan, melemparkan atau membidikkan. Hal ini berkaitan dengan pendidikan, di mana seorang pengajar harus menentu-kan dengan jelas sasaran yang akan dicapai dalam mengajar.

Keenam, Zakar (Kel. 18:20). Artinya menyinari atau menerangi. Hubungannya dengan pendidikan ialah seorang guru harus memberikan penjelasan sebaik mungkin kepada peserta didik agar dapat memahami dengan jelas apa yang disampaikan.
Ketujuh, Hakam (Ams. 5:13). Artinya men-jadi bijaksana atau berhikmat. Dalam kaitannya dengan pen-didikan berarti salah satu tujuan akhir mengajar ialah agar peserta didik menjadi orang yang bijaksana atau orang yang berhikmat.

Kedelapan, Sakal (Ams. 16:20). Artinya mendapat pandangan baru. Jika dikaitkan dengan pendidikan berarti guru memberikan pengajaran dan peserta didik mendapatkan pandangan yang baru.

Kesembilan, Ra-ah (Ams. 6:6). Artinya melihat secara rinci. Istilah ini berkaitan dengan pendidikan di mana seorang guru memberikan penjelasan, sehingga peserta didik dapat melihat secara rinci. Dengan kata lain peserta didik dapat melihat secara deteil oleh karena adanya penjelasan yang memadai.

\section{Perjanjian Baru}

Pertama, Didasko. Istilah didasko diungkapkan 95 kali dalam PB. Didasko mengandung arti menggambarkan, memanggil untuk mengambil keputusan, menyapa orang dengan kehendak Allah bagi mereka secara utuh. Di samping itu, istilah ini da-pat juga berarti menyalurkan seperangkat doktrin yang harus dikuasai agar dapat lestari.

Kedua, Paideuo. Berarti memberikan bimbingan, mengajar dan melatih. Istilah ini umunya digunakan dalam kaitan dengan memelihara anak. Juga dapat dimak-sudkan sebagai tindakan korektif dan disiplin dalam pengajaran. Kata kerja paideuo berasal dari kata benda paidia yang berarti seorang anak kecil. Dengan istilah ini mengajar berarti memberikan bimbingan, latihan dan disiplin (Kis. 7:22; 22:3; I kor. 11:32; I Tim. 1:20; II Tim. 2:25; Ef. 6:4). Dari kata ini muncul istilah yang berkaitan dengan ilmu mengajar dan dinamakan paedagogi.

Ketiga, Noutheteo. Berarti memberi latihan melalui perkataan yang membangun semangat dan yang menegur. Secara harafiah berarti mempertajam 
pikiran. Tugas mengajar berarti memberikan semangat, memberikan koreksi dan nasehat-nasehat yang sifatnya berhadapan langsung (I Kor. 4:4; 10:11; Ef. 6:4; Kol. 1:28; 3:16).

Keempat, Katekeo. Berarti mengemukakan informasi, menyampaikan fakta, melaporkan atau memberikan kabar atau gagasan atau masukan. Dari kata inilah muncul istilah katekisasi dalam pengajaran iman Kristen. Katekisasi sebenarnya merupakan salah satu pendekatan dalam mengajar, yakni membeberkan fakta dan keterangan tentang iman. Hasilnya, orang dibentuk oleh apa yang didengar atau dipelajarinya (Luk. 1:4; Kis. 18:25; 21:21; Rm. 2:18; I Kor. 14:19; Gal. 6:6).

Kelima, Matheteuo. Berarti menjadikan murid. Seorang murid memiliki loyalitas dan pengabdian. Seorang murid (mathetes) juga berarti seorang pribadi yang belajar secara cermat melalui pengamatan. Istilah ini secara khusus terdapat dalam Injil Matius 28:19; 11:28-29. Dengan pengertian ini mengajar merupakan usaha membimbing orang untuk memiliki loyalitas dan pengabdian kepada Yesus Kristus. Seorang pengajar dalam tugasnya inenyampaikan apa yang didengar dan dipelajari secara saksama dari apa yang telah dialaminya kepada peserta didiknya.

Keenam, Oikodomeo. Artinya membangun atau membentuk. Arti lain dari kata ini ialah mendidik dalam usaha meningkatkan kualitas kehidupan rohani sehingga orang bertumbuh menuju kedewasan rohani. Mengajar adalah usaha memba-nguii mutu rohani orang lain (I Kor. 3:9; 8:1; I Tes. 5:1; I Pet. 2:5)

Ketujuh, Manthano. Artinya belajar melalui praktek, perbuatan dan pengalaman. Dengan demikian mengajar adalah upaya mendorong orang belajar lewat tindakan nyata (Ibr. 5:8; fil. 4:11; Mat. 11:29; Ef. 4:20).

Kedelapan, Ektithemi. Artinya mengungkapkan dan menjelaskan fakta secara logis. Perbuatan demikian penting dan lasim dala:n rangka mempertahankan ajaran atau mengemukakan ceritera (Kis. $11: 4 ; 18: 25 ; 28: 23)$.

Kesembilan, Diermeneuo. Menerjemahkan atau menafsirkan. Dari kata ini muncul istilah hermeneutik, yakni langkah, prinsip, dan teknik menafsir (Luk. 24:47). Menafsir berarti menyingkapkan makna kebenaran rohani Kitab Suci. Demikian juga dengan tugas mengajar yakni memampukan orang untuk menafsirkan apa yang dipelajarinya sehingga bermakna dalam kehidupan sehari-hari.

Kesepuluh, Dianoigo. Merupakan istilah yang ditujukan kepada perbuatan Allah dalam membuka pikiran dan hati manusia terhadap kebenaran rohani (Mar. 7:34,35; Luk. 24:31,45; Kis. 16:14). Dalam kegiatan meng ajar, pengajar memimpin peserta didiknya untuk mengalami sentuhan atau urapan Tuhan, yang berkenan me-nyingkapkan kebenar-an sejati.

Dalam pemahaman terhadap beberapa istilah di atas, nyata bahwa tugas mengajar adalah sangat penting dan sangat mendesak. Tugas ini amat berharga dalam rangka membimbing orang ke arah pengenalan diri sendiri, pengenalan akan Tuhan dan sesama manusia. Selain itu, kegiatan mendidik melibatkan berbagai cara dan strategi untuk membengkitkan minat seseorang memasuki peristiwa belajar.

\section{Penutup}

Pendidikan Kristen dalam jemaat merupakan pokok yang sentral dalam pelayanan penggembalaan. Melalui pendidikan Kristen seseorang dapat dituntun untuk datang dan mengenal Kristus, melalui perjumpaan dengan Tuhan mereka terus dibangun untuk hidup bersama-sama dengan Allah di bawah bimbingan Roh Kudus dan di dalam persekutuan dengan Kristus, sehingga 
jemaat semakin bertumbuh menuju kedewasan di dalam Kristus. Pendidikan Kristen yang benar-benar di tengah-tengah jemaat merupakan ketaatan kepada panggilan pemuridan. Pemuridan yang terencana, terarah dan berkesinambungan akan menghasilkan murid sejati yang pada akhirnya akan menghasilkan murid sejati lagi.

Kedudukan pendidikan Kristen dalam jemaat merupakan hal yan pokok sebab merupakan panggilan ilahi dan dasar pengembalaan jemaat. Ketidakseimbangan program pendidikan Kristen dengan program pendidikan lainnya dalam jemaat merupakan kekeliruan besar.

Pendidikan Kristen dalam jemaat merupakan sesuatu yang penting sebab hal mendidik adalah program Allah sendiri, diperintahkan dan diberkati Allah. Yesus sendiri mengutamakan dan memerintahkan pendidikan Kristen. Gereja mula-mula menjalankan pendidikan Kristen dan gereja berkembang. Rasul Paulus mementingkan pendidikan Kristen. Pendidikan Kristen dibutuhkan dan sangat bermanfaat serta mengandung dinamika.

\section{Endnotes:}

1 Ruth F. Selan, "Arti Pendidikan Kristen," Rubrik Pendidikan Kristen seri 1:2.

2 Jackie L. Smallbones, Cristian Educations Jurnal $X$, No.2 (Spring 1990):55.

3 Eddy Leo, Murid Sejati, Suatu Pilihan Mutlak (Jakarta: Metanoia Publishing, 2003), i-iii

4 Robert R. Boehle, Sejara Perkembangan Pikiran dan Praktek Pendidikan Agama Kristen (Jakarta:BPK, 2000), viii.

5 Kenneth O. Gangel, Membina Pemimpin Pendidikan Kristen (Malang: Gandum Mas, 2001), 9.

6 J. L Ch. Abineno, Sekitar Katekese Gerejawi (Jarkata: BPK Gunung Mulia, 1989), 22.

7 Jackie L. Smallbones, "Education People to Be Christian, "Christian Education Journal X, No2 (Spring 1990): 56.

8 Sylvia Soeherman, "Tujuan Pengajaran Gereja dan Implikasinya," Vertas, Jurnal Teologi dan Pelayanan, Vol 4, No.1 (April 2003):119.

9 B. Samuel Sijabat, Strategi Pendidikan Kristen, Suatu Tinjauan Teologis-Filosofis (Yogyakarta: Yayasan Andi, 1994), 10
${ }^{10}$ Robert W. Passino, Strategi Pendidikan Kristen (Yogyakarta: Yayasan Andi 1994), 10

11 Iris Cully, Christian Education: Istruction or Nature, Religius Education (New York: May-Juni, 1967), 225.

${ }^{12}$ Eli Tanya, Gereja dan Pendidikan Agama Kristen (Sidang Laya-Cianjur:STTC, 1999), 31

${ }^{13}$ Ruth F. Selan, "Arti Pendidikan Kristen," Rubrik Pendidikan Kristen seri 1:2-3.

14 Robert R. Boehlke, Sejarah Perkembangan Pikiran dan Praktek Pendidikan Agama Kristen (Jakarta: BPK, 1997), 501.

${ }^{15}$ Lelia Lewis, "Pentingnya Pendidikan Kristen," Rubrik Pendidikan Kristen Seri 1, n.d, 3.

${ }^{16}$ Norman E. Thomas, Transformasi Misi Kristen, Teks-teks Klasik Tentang Misi dan Kekristenan Sedunia (Jakarta: BPK, 2000), 163.

\section{Kepustakaan}

Abineno, JL. Ch., Sekitar Katekese Gerejawi. Jakarta: BPK, 1989.

Boehle, Robert R. Sejarah Perkembangan Pikiran dan Praktek Pendidikan Agama Kristen. Jakarta: BPK, 2000.

Cully, Iris. Christian Education: Istruction or Nurture, Religius Education. New York: May-Juni, 1967.

Gangel, Kenneth O. Membina Pemimpin Pendidikan Kristen. Malang: Gandum Mas, 2001.

Leo, Eddy. Murid Sejati, Suatu Pilihan Mutlak. Jakarta: Metanoia Publishing, 2003.

Lewis, Lelia. "Pentingnya Pendidikan Kristen," Rubrik Pendidikan Kristen Seri 1, n.d, 3.

Passino, Robert W. Strategi Pendidikan Kristen. Yogyakarta: Yayasan Andi, 1994, 10.

Boehle, Robert R. Pendeta dan Peranan Pedagogisnya, Tabah Melangkah. Jakarta: STT Jakarta, 1984.

Selan, Ruth F. "Arti Pendidikan Kristen," Rubrik Pendidikan Kristen seri 1, n.d.

Sijabat, B. Samuel. Strategi Pendidikan Kristen, Suatu Tinjauan TeologisFilosofis. Yogyakarta: Yayasan Andi, 1994. 
Smallbones, Jackie L. Christian Educations Journal X, No. 2 (Spring, 1990).

Smallbones, Jackie L. "Education People to Be Christian," Chiristian Education Jaournal X, No. 2 (Spring 1990).

Soeherman, Sylvia. "Tujuan Pengajaran Gereja dan Implikasinya," Veritas, Jurnal Teologi dan Pelayanan, Vol. 4, No. 1 (April, 2003).
Tanya, Eli. Gereja dan Pendidikan Agama Kristen. Sidang Laya-Cianjur: STTC, 1999.

Thomas, Norman E. Teks-Teks Klasik Tentang Misi dan Kekristenan. Jakarta: BPK, 2000. 